\title{
Contouring the Emergence Profile of Peri-implant Soft Tissue by Provisionals on Implants - Case Report
}

\author{
Vojkan Lazić, Ana Todorović, Igor Djordjević, Nataša Milošević, Danica Popović, Ana Miletić \\ University of Belgrade, Faculty of Dental Medicine, Department for Prosthodontics, Belgrade, Serbia
}

\begin{abstract}
SUMMARY
Aesthetic outcome of implant therapy involves the appropriate architecture of peri-implant soft tissue and interdental papilla. The dynamic compression technique of soft tissue is mentioned in contemporary literature as one of the methods for achieving optimal emergence profile. The aim of this case report was to present soft tissue prosthetic modeling with temporary crowns on implants for obtaining an emergence profile of final restoration. A 25-year-old female patient with missing left maxillary central incisor was referred to the Department of Oral Surgery School of Dental Medicine University in Belgrade for dental implant placement. After detailed planning, implant placement of Straumann Bone level implant NC $\varnothing 3,3 \times 12$ mm (Straumann ${ }^{\circledR}$ Bone Level NC), in the position of 21 was performed. Upon completion of osseointegration period, screw retained laboratory temporary crown was fabricated. During the next 3 months emergence profile was scalloped by creating additional pressure on the soft tissue with periodic adding the composite resin material to a temporary crown. The created emergence profile was transferred to the master cast by using customized impression coping, making possible fabrication of the final implant restoration according to the design made with provisional restoration. Soft tissue conditioning using temporary dental restorations on implants presents a non-invasive method with predictable aesthetic result.
\end{abstract}

Keywords: dynamic compression; emergence profile; dental implants

\section{INTRODUCTION}

Traditionally, one of the main objectives of an implant treatment has been to ensure osseointegration [1-4]. On the other hand, the achievement of implant osseointegration does not always correlate with successful esthetic outcome [5]. In the early period of implant dentistry, implants were placed with a "Bone driven implant placement concept". According to this concept, an implant is placed at the crest of the bone, which has a sufficient amount of the bone, however, this is not always an ideal implant position for the final restoration. Therefore, this could result in an unaesthetic and nonfunctional implant restoration. Recently, with the development of several bone grafting materials, guided bone regeneration (GBR) techniques, and improvement of technology of implant surface treatment, the concept of implant treatment has been changed to "Prosthetically driven implantation" [6]. Consequently, there is now an increased demand for aesthetic restorations with healthy peri-implant soft tissue.

The emergence profile is one of the key factors in the establishment of the optimum hard and soft tissues. In particular, in the esthetic zone, the emergence profile of dental implant restorations should mimic natural teeth [7, 8]. Improperly contoured restorations will cause compromised access for oral hygiene and inflamed soft tissue that can induce unaesthetic results [9]. Accordingly, properly contoured restoration with a natural emergence profile and gingival architecture that harmonizes with adjacent teeth is very important for aesthetic and functional im- plant therapy [10]. To achieve an optimal emergence profile, several factors need to be considered from the initial to the final stages of the treatment. In the presence of an appropriate tissue base, achieving an optimal emergence profile depends on the selection of implant, healing abutment, and intermediate prosthetic element selection.

The term "emergence profile" was first used in 1977 by Stein and Kuwata [11] to describe tooth and crown contours as they traversed soft tissue and rise toward the contact area interproximally and height of contour buccally and lingually. In 1990, a photographic analysis of natural teeth by Croll [12] confirmed that most emergence profiles are relatively straight as opposed to convex or concave. If a restoration introduced a convexity or concavity where it didn't belong, the unnatural contour might trap plaque or otherwise disrupt gingiva. Since the introduction of dental implants, there has been renewed interest in this concept as dentists attempt to replicate not only the crown but also the entire tooth anatomy. Unnatural emergence contours may trap plaque and be difficult to maintain hygienically. Additionally, human eye may detect a final restoration in the esthetic zone that has not faithfully reproduced what nature originally provided.

Neale and Chee [7] in 1994 were perhaps the first to describe a technique for surgically sculpting soft tissue around an implant to more closely mimic nature. More recent published technique describes modifying provisional crowns incrementally rather than a surgical approach [13]. 


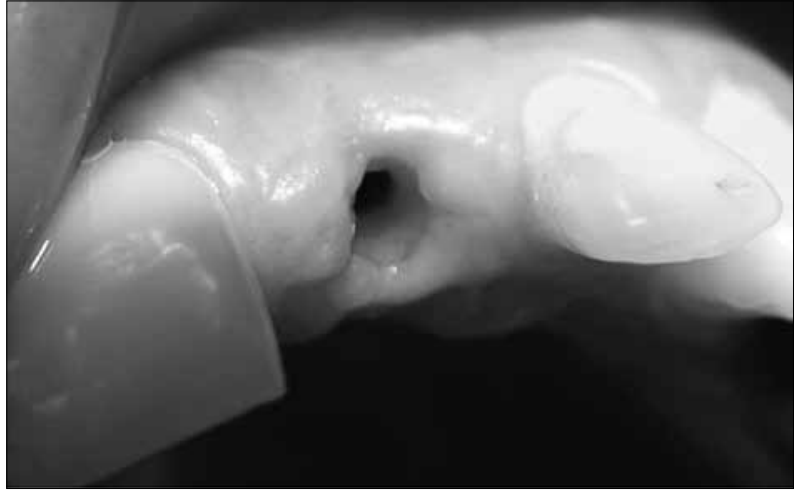

Figure 1. Narrow and round appearance of emergence profile after 15 days

Slika 1. Okrugao i isuviše uzan izgled izlaznog profila 15 dana posle otvaranja implantata

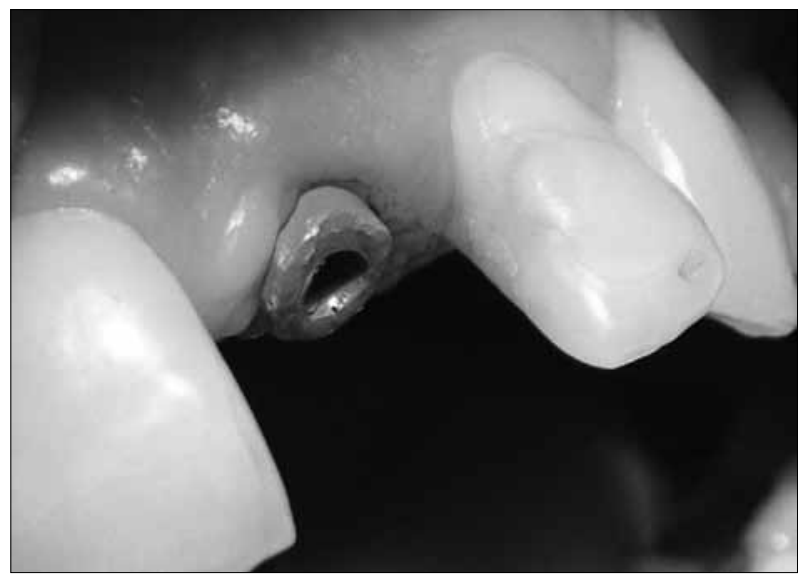

Figure 2. Customizable healing cap placed Slika 2. Postavljena prilagodljiva kapica za zarastanje

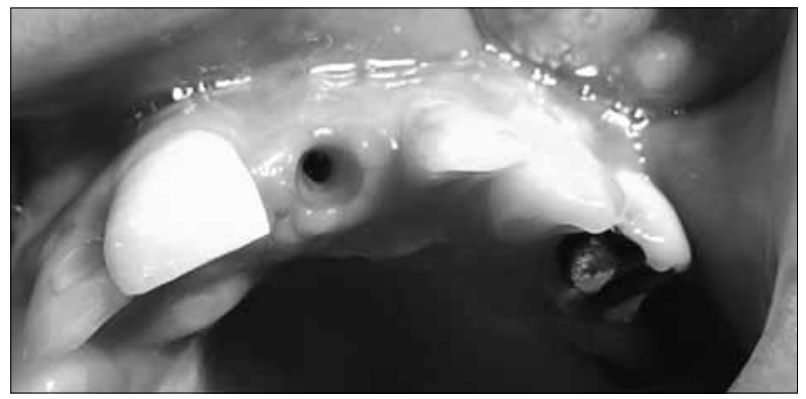

Figure 3. Appearance of soft tissue one month after customizable healing abutment is removed

Slika 3. Izgled mekog tkiva 30 dana po uklanjanju prilagodljive kapice za zarastanje

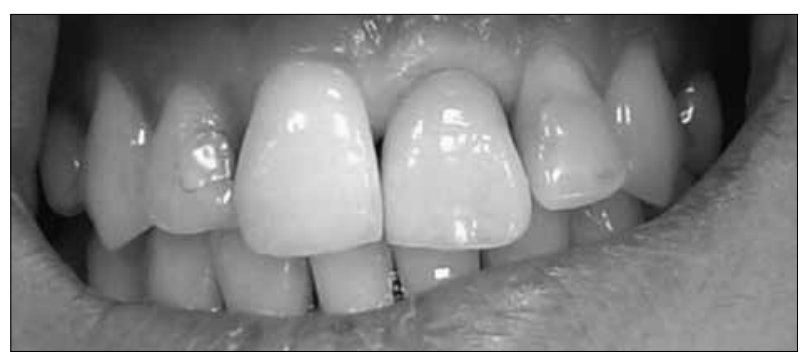

Figure 4. Insertion of implant-supported screw-retained provisional restoration. Ischemic reaction is visible

Slika 4. Postavljena privremena nadoknada retinirana šrafom. Vidljiva je ishemijska reakcija

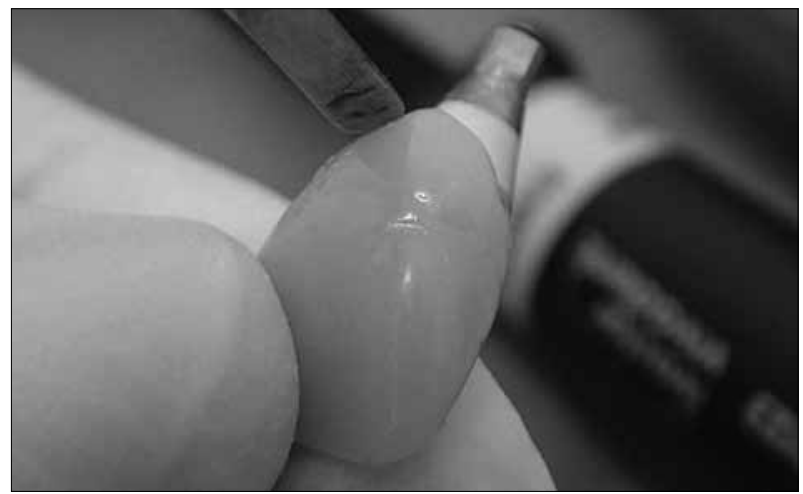

Figure 5. Scalloping of emergence profile with periodic adding of composite material on provisional restoration

Slika 5. Oblikovanje izlaznog profila privremenom nadoknadom uz periodično dodavanje kompozitnog materijala

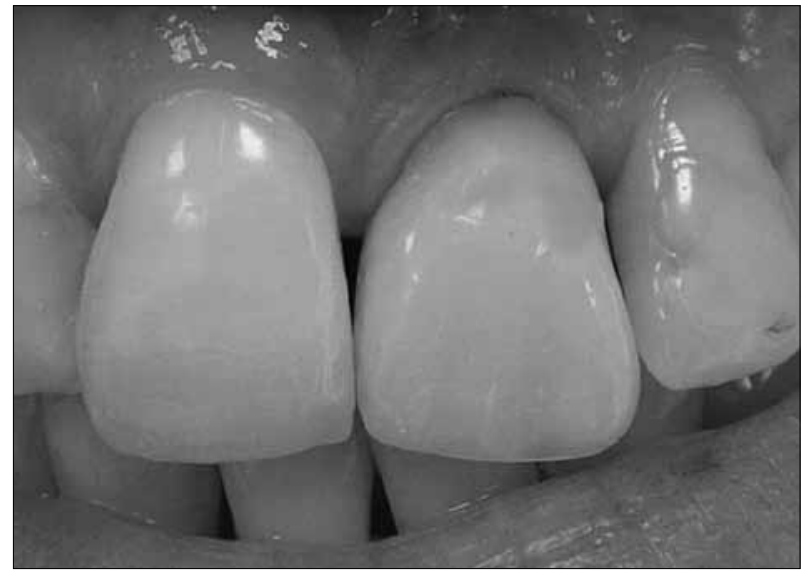

Figure 6. Emergence profile with provisional restoration 90 days later Slika 6. Izlazni profil s privremenom krunicom posle 90 dana

The aim of this paper was to present gingival recontouring by fabricating and adjusting provisional implant restoration to produce an optimal emergence profile for the final implant restoration.

\section{CASE REPORT}

A 25-year-old female patient with missing left maxillary central incisor without periodontal/implant risk factors was referred to the department of Oral Surgery School of Dental Medicine University in Belgrade for dental implant placement. According to the protocol of prosthetically driven implantation, implant placement of Straumann Bone level implant NC Ø 3,3×12 mm (Straumann ${ }^{\circledR}$ Bone Level NC), in the position of 21 was performed.

After period of oseointegration implant was "opened" and healing abutment was placed (Figure 1). After 15 days, emergence profile was too narrow and customizable healing abutment was positioned (Figures 2 and 3). One month later open tray impression with addition silicone was performed. Laboratory-processed, screw-retained provisional restoration was made on the temporary abutment. The provisional was made from light- and heatcuring microfilled composite (Adoro SR, Ivoclar Vivadent $A G)$. The material was contoured and highly polished to 


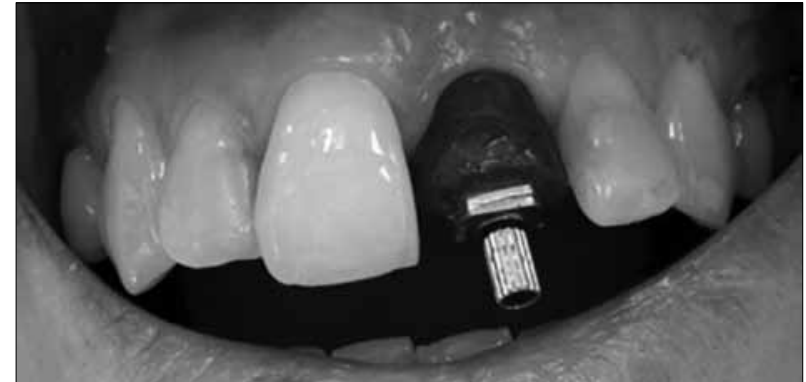

Figure 7. Customized impression coping for the open tray technique

Slika 7. Postavljen individualizovani transfer pozicije implantata za otisak metodom otvorene kašike

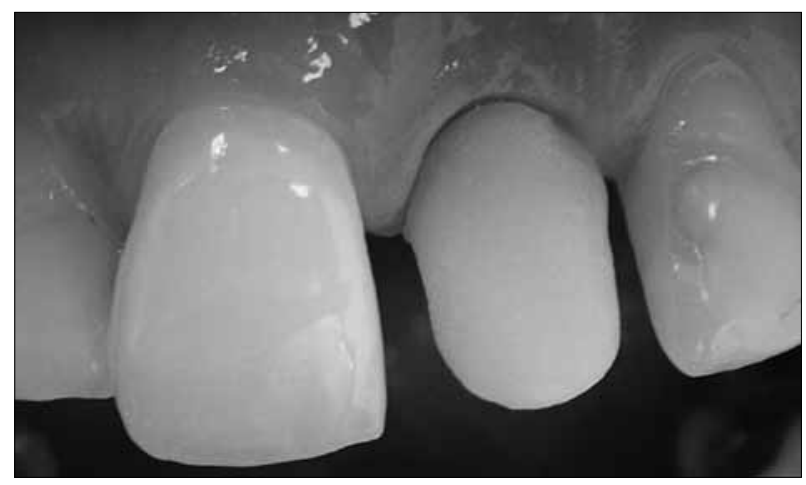

Figure 8. The IPS e.max Press hybrid abutment made of lithium disilicate on the titanium base (Ti base, Straumann)

Slika 8. IPS e.max Press hibridni abatment od litijum-disilikata na bazi titanijuma (Ti base, Straumann)

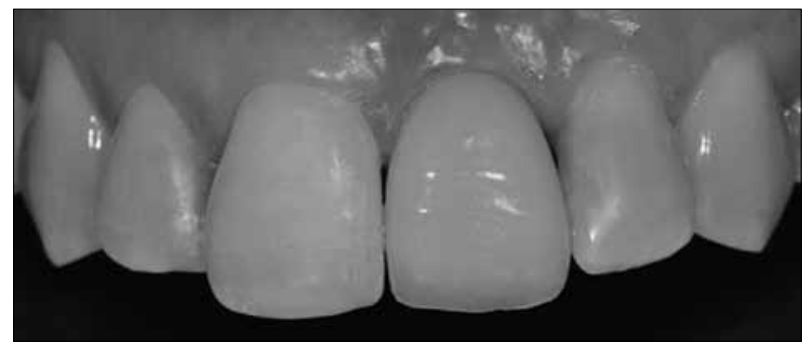

Figure 9. Final all-ceramic screw retained single crown in situ Slika 9. Definitivna keramička krunica retinirana šrafom in situ

minimize plaque accumulation and tissue irritation (Figure 4). During the next 3 months emergence profile was scalloped with periodic creating additional pressure on soft peri-implant tissue by adding material on the provisional restoration (Figures 5 and 6). After completion of soft-tissue conditioning and maturing phase, created emergence profile was transferred to the master cast by using customized impression coping (Figure 7). The identical soft-tissue profile in the master cast was established intra-orally, making possible the fabrication of the final implant restoration according to the design made with the provisional restoration (Figures 8 and 9).

\section{DISCUSSION}

Aesthetic result of implant restorations depends on prosthetically and biologically driven implant placement [14], visually satisfying restoration $[15,16]$ and architecture of the surrounding peri-implant soft tissue [17]. The evolution of concept of the surgical implant therapy has led to improved osseointegration, but even after the successful surgical approach, prosthetic management of soft tissue in the esthetic zone is a challenge.

Techniques that present soft tissue shaping with provisional restorations on implants can not be found in the literature, and only a few case studies on this topic have been published. So far the only presented technique of peri-implant soft tissue modeling is by adding composite resin to a provisional during the period of the soft tissue conditioning $[18,19]$. In the initial phase, it is important to squeeze the tissue into the right direction. This is especially important in the papillary region where tissue will not have enough space to mature and fill in the space for papilla due to slightly overcontoured temporary crown after addition of composite material. So the dynamic compression method uses the pressure in the initial stage as round shaped emergence profile is achieved with transmucosal healing cap. Pressure is increased in several steps in order to avoid necrosis, anemia or pain. Pressure with the provisional restoration pushes soft tissue laterally in order to direct it in the right way, but it is also important that temporary restoration is undercontoured, particularly in the area of papilla, so that the tissue could be designed to fill in the created space. The presented modification of temporary crown technique is of crucial importance to finalize the architecture of soft tissue and improve the aesthetic result. Conditioning the soft tissue with provisional restoration represents, compared to the surgical technique, less invasive method with predictable aesthetic outcome. Its primary disadvantage is that it takes a longer time. To confirm the validity of this new technique clinical studies are necessary to examine the long-term stability of peri-implant soft tissue as well as in vivo histological analysis that would show precise structure of formed tissue.

Dynamic compression technique in the esthetic zone is a clinical method based on the initial pressure and subsequent modification of provisional restoration by creating space in the papillary region. Our clinical outcome, with a limit of one case report, showed that temporary crown can be used to form the emergence profile of peri-implant soft tissue in harmony with the adjacent teeth, as well as to achieve proper height and width of interdental papilla. Temporary crown also facilitates communication between the patient, dentist and dental technician and provides predictable and extraordinary aesthetic result with final restoration.

\section{ACKNOWLEDGEMENTS}

The authors express their gratitude to the dental technician Dragan Spasojević. 


\section{REFERENCES}

1. Andersson B, Odman P, Lindvall AM, Lithner B. Single-tooth restorations supported by osseointegrated implants: results and experiences from a prospective study after 2 to 3 years. Int J Oral Maxillofac Implants. 1995; 10:702-11. [PMID: 8530173]

2. Avivi-Arber L, Zarb GA. Clinical effectiveness of implant-supported single-tooth replacement: the Toronto Study. Int J Oral Maxillofac Implants. 1996; 11:311-21. [PMID: 8752552]

3. Jemt T, Pettersson P. A 3-year follow-up study on single implant treatment. J Dent. 1993; 21:203-8.

[DOI: 10.1016/0300-5712(93)90127-C] [PMID: 8354744]

4. Priest GF. Failure rates of restorations for single-tooth replacement. Int J Prosthodont. 1996; 9:38-45. [PMID: 8630176]

5. Levine RA. Soft tissue considerations for optimizing implant esthetics. Funct Esthet Restor Dent. 2007; 1:54-62.

6. Garber DA, Belser UC. Restoration-driven implant placement with restoration-generated site development. Compend Contin Educ Dent. 1995; 16:796, 798-802, 804. [PMID: 8620398]

7. Neale D, Chee WW. Development of implant soft tissue emergence profile: a technique. J Prosthet Dent. 1994; 71:364-8. [DOI: 10.1016/0022-3913(94)90095-7] [PMID: 8195999]

8. Jansen CE. Guided soft tissue healing in implant dentistry. ( Calif Dent Assoc. 1995; 23:57-58. 60, 62 passim. [PMID: 7673996]

9. Su H, Gonzalez-Martin O, Weisgold A, Lee E. Considerations of implant abutment and crown contour: critical contour and subcritical contour. Int J Periodontics Restorative Dent. 2010; 30:335-43. [DOI: 10.11607/prd.00.0933] [PMID: 20664835]

10. Wöhrle PS. Nobel perfect esthetic scalloped implant: rationale for a new design. Clin Implant Dent Relat Res. 2003; 5(Suppl 1):64-73. [DOI: 10.1111/j.1708-8208.2003.tb00017.x] [PMID: 12691652]

11. Stein RS, Kuwata M. A dentist and a dental technologist analyze current ceramo-metal procedures. Dent Clin North Am. 1977; 21:729-49. [PMID: 332541]
12. Croll BM. Emergence profiles in natural tooth contour. Part II: Clinical considerations. J Prosthet Dent. 1990; 63:374-9. [DOI: 10.1016/0022-3913(90)90223-Y] [PMID: 2184220]

13. Wittneben JG, Buser D, Belser UC, Braegger U. Peri implant soft tissue conditioning with provisional restorations in the esthetic zone: the dynamic compression technique. Int I periodontics Restorative Dent. 2013; 33:447-55. [DOI: 10.11607/prd.1268] [PMID: 23820704]

14. Brugnami F, Caleffi C. Prosthetically driven implant placement. How to achieve the appropriate implant site development. Keio J Med. 2005; 54:172-8. [DOl: 10.2302/kjm.54.172] [PMID: 16452826]

15. Cooper LF. Objective criteria: guiding and evaluating dental implant esthetics. J Esthet Restor Dent. 2008; 20:195-205. [DOI: 10.1111/j.1708-8240.2008.00178.x] [PMID: 18533983]

16. Buser D, Wittneben J, Bornstein MM, Grutter L, Chappuis V, Belser UC. Stability of contour augmentation and esthetic outcomes of implant-supported single crowns in the esthetic zone: 3-year results of a prospective study with early implant placement postextraction. J Periodontol. 2011; 82:342-9. [DOI: 10.1902/jop.2010.100408] [PMID: 20831371]

17. Hermann JS, Buser D, Schenk RK, Higginbottom FL, Cochran DL. Biologic width around titanium implants. A physiologically formed and stable dimension over time. Clin Oral Implants Res. 2000; 11:1-11. [DOI: 10.1034/j.1600-0501.2000.011001001.x] [PMID: 11168188]

18. Santosa RE. Provisional restoration options in implant dentistry. Aust Dent J. 2007; 52:234-42. [DOl: 10.1111/j.1834-7819.2007.tb00494.x] [PMID: 17969293]

19. Priest G. Esthetic potential of single-implant provisional restorations: selection criteria of available alternatives. J Esthet Restor Dent. 2006; 18:326-38. [DOI: 10.1111/j.1708-8240.2006.00044.x] [PMID: 17083437]

Received: 01/07/2015 • Accepted: 09/11/2015 


\title{
Oblikovanje mekih tkiva privremenim zubnim nadoknadama na implantatima - prikaz slučaja
}

\author{
Vojkan Lazić, Ana Todorović, Igor Đorđević, Nataša Milošević, Danica Popović, Ana Miletić \\ Univerzitet u Beogradu, Stomatološki fakultet, Klinika za stomatološku protetiku, Beograd, Srbija
}

\begin{abstract}
KRATAK SADRŽAJ
Estetski uspeh implantološke terapije podrazumeva odgovarajuću arhitekturu periimplantatnih mekih tkiva i interdentalne papile. Tehnika dinamičke kompresije mekih tkiva pominje se u savremenoj literaturi kao jedna od metoda za postizanje optimalnog izlaznog profila. Cilj ovog rada je bio da se predstavi mogućnost protetičkog modelovanja mekih tkiva zubnom nadoknadom na implantatu za dobijanje izlaznog profila definitivne nadoknade. Žena stara 25 godina sa nedostatkom centralnog sekutića u gornjoj vilici s leve strane upućena je na Kliniku za oralnu hirurgiju Stomatološkog fakulteta Univerziteta u Beogradu radi ugradnje implantata. Posle detaljnog planiranja, u predelu zuba 21 ugrađen je Straumann Bone level implant NC Ø 3,3×12,0 mm (Straumann ${ }^{\circ}$ Bone Level NC). Po završenom periodu oseointegracije izrađena je laboratorijska privremena krunica retinirana zavrtnjem. Tokom sledeća tri meseca izlazni profil je oblikovan periodičnim stvaranjem dodatnog pritiska na meka tkiva dodavanjem kompozitnog materijala na privremenu krunicu. Izlazni mekotkivni profil je pomoću individualizovanog transfera pozicije implantata prenet na radni model, što je omogućilo izradu konačne keramičke hibridne krunice prema dizajnu koji je kreiran privremenom nadoknadom. Priprema mekih tkiva privremenim zubnim nadoknadama na implantatima je neinvazivna klinička metoda s predvidljivim estetskim rezultatom $\mathrm{i}$ zadovoljavajućom visinom i širinom interdentalne papile.

Ključne reči: dinamička kompresija; izlazni profil; zubni implantati
\end{abstract}

\section{UVOD}

Tradicionalno, jedan od glavnih ciljeva terapije implantatima jeste da se osigura oseointegracija [1-4]. Međutim, s druge strane, ostvarena oseointegracija implantata nije uvek u korelaciji s uspešnim estetskim rezultatom terapije zubnim nadoknadama na implantatima [5]. U ranom periodu stomatološke implantologije važio je koncept „implantologija vođena raspoloživom kosti“. Prema ovom konceptu, implantat je postavljan na mestu koje ima dovoljnu količinu kosti, ali to često nije bio idealan položaj implantata za zubne nadoknade. Dakle, ovakav koncept je dovodio do nastanka neestetskih i nefunkcionalnih nadoknada na implantatima. S razvojem materijala za vođenu koštanu regeneraciju (engl. guided bone regeneration) i unapređenjem tehnologije izrade površine implantata, koncept terapije implantatima je promenjen $\mathrm{u}$,protetičko vođenje ugradnje implantata" [6]. Shodno tome, sada postoji veća potreba za estetskim nadoknadama na implantatima sa zdravim periimplantatnim mekim tkivom.

Izlazni profil gingive je jedan od ključnih faktora u formiranju optimalnog odnosa tvrdih i mekih tkiva. Konkretno, u estetskoj zoni odgovarajući izlazni profil nadoknada na implantatima treba da potpuno oponaša prirodne zube $[7,8]$. Nepravilno konturirane nadoknade će otežati održavanje oralne higijene, što dovodi do upale mekog tkiva i neestetskog ishoda lečenja [9]. Izrada odgovarajućih nadoknada s prirodnim izlaznim profilom i odgovarajućom arhitekturom gingive koja je usklađena sa susednim zubima je važan preduslov za uspešnu estetsku i funkcionalnu implantatnu terapiju [10].Za postizanje optimalnog izlaznog profila nekoliko faktora treba uzeti u obzir od početka do krajnjih faza lečenja. Postojanje zdravog mekog tkiva je preduslov za postizanje izlaznog profila, koji zavisi od pravilnog izbora implantata, odgovarajuće kapice za zarastanje gingive i pravilnog odabira protetičkih elemenata implantata.

Pojam ,izlazni profil“ prvi put su upotrebili 1977. godine Stajn (Stein) i Kuvata (Kuwata) [11] kako bi opisali zub i konture krunice u odnosu na meka tkiva u interproksimalnoj zoni, kao i na visinu konture gingive vestibularno i lingvalno. Foto- grafska analiza prirodnih zuba koju je uradio Krol (Croll) [12] 1990. godine potvrdila je da je većina izlaznih profila relativno ravna nasuprot konveksnim ili konkavnim oblicima. Ukoliko je nadoknada isuviše konveksna ili konkavna, takva neprirodna kontura može da doprinosi većoj prijemčivosti plaka ili poremećaju oblika gingive. Od uvođenja dentalnih implantata teži se protetičkoj restauraciji zubnim nadoknadama anatomskog (prirodnog) oblika. Nepravilan odnos izlaznog profila desni i nadoknade na implantatima (ukoliko nije verno reprodukovano) može se veoma lako, uočiti pogotovo u estetskoj zoni.

Nil (Neale) i Či (Chee) [7] su 1994. godine prvi opisali tehniku za hirurško estetsko oblikovanje mekog tkiva oko implantata. Novija istraživanja daju prednost tehnici dinamičke kompresije, tj. postepenom modifikovanju privremenih krunica na implantatima, i na taj način postizanju željenog izlaznog profila gingive u odnosu na hirurški pristup [13].

Cilj ovog rada je bio da predstavi klinički slučaj preoblikovanja gingive pomoću postupka postepenog prilagođavanja privremene zubne nadoknade na implantatu radi dobijanja optimalnog izlaznog profila definitivne nadoknade.

\section{PRIKAZ SLUČAJA}

Žena stara 25 godina s nedostatkom centralnog sekutića u gornjoj vilici s leve strane, bez faktora rizika za implantološku terapiju, upućena je na Kliniku za oralnu hirurgiju Stomatološkog fakulteta Univerziteta u Beogradu radi ugradnje implantata. Prema protokolu protetičkog vođenja, u predelu zuba 21 izvršena je ugradnja Straumann Bone level implantata NC $\emptyset 3,3 \times 12,0$ mm (Straumann ${ }^{\circledast}$ Bone Level NC). Posle perioda oseointegracije implantat je otvoren i postavljena je kapica za zarastanje (Slika 1). Nakon 15 dana izlazni profil je bio isuviše uzan, pa je korišćena prilagodljiva kapica za zarastanje (Slike $2 \mathrm{i}$ 3). Mesec dana kasnije realizovan je jednofazni otisak adicionim silikonom i metodom otvorene kašike, kako bi bila izrađena laboratorijska, šrafom retinirana krunica na privremenom abatmentu. Privremena krunica izrađena je od mikropunjenog 
kompozita sa dvojnom, toplotno-svetlosnom polimerizacijom (Adoro SR, Ivoclar Vivadent AG). Materijal je tako oblikovan i visoko ispoliran, kako bi se smanjili nagomilavanje plaka i iritacija tkiva (Slika 4). Tokom sledeća tri meseca izlazni profil je oblikovan periodičnim stvaranjem dodatnog pritiska na meko periimplantatno tkivo dodavanjem kompozitnog materijala na privremenu nadoknadu (Slike 5 i 6). Posle završene pripreme mekog tkiva dobijeni izlazni profil je prebačen na radni model korišćenjem individualizovanog transfera pozicije implantata (Slika 7). Mekotkivni profil postignut intraoralno prenet na radni model je omogućio izradu definitivne nadoknade prema dizajnu uspostavljenom privremenom nadoknadom (Slike 8 i 9).

\section{DISKUSIJA}

Estetski rezultat nadoknada na implantatima zavisi od protetički i biološki vođene ugradnje implantata [14], vizuelno zadovoljavajuće nadoknade $[15,16]$ i arhitekture okolnog periimplantatnog mekog tkiva [17]. Evolucija hirurškog koncepta implantološke terapije dovela je do poboljšanja oseointegracije, ali čak i nakon uspešnog hirurškog pristupa protetički menadžment mekog tkiva u estetskoj zoni predstavlja izazov.

U literaturi se ne mogu pronaći opisi tehnika koje oblikuju meka tkiva privremenim nadoknadama na implantatima, a objavljeno je samo nekoliko prikaza slučaja na ovu temu. Dosad je jedino prikazana tehnika modifikovanja periimplantatnih mekih tkiva dodavanjem kompozita na privremenu nadoknadu tokom perioda kondicioniranja mekog tkiva $[18,19]$. U inicijalnoj fazi važno je da se tkivo potisne u pravom smeru. To je naročito važno u papilarnom predelu, gde tkivo neće imati prostora da sazri i ispuni prostor za papilu, jer će privremena krunica biti blago povećana usled dodavanja kompozitnog materijala. Dakle, metoda dinamičke kompresije koristi pritisak u inicijalnoj fazi, jer je transmukoznom kapicom za zarastanje formiran okrugli oblik izlaznog profila. Pritisak se povećava u nekoliko koraka, kako bi se izbegli nekroza, anemija ili bol. Pritisak privremenom nadoknadom potiskuje meko tkivo lateralno, da bi ga usmerila u pravom smeru, a takođe je važno da se privremena krunica redukuje, naročito u predelu papile, kako bi tkivo moglo da ispuni stvoreni prostor. U prikazanoj tehnici modifikacija privremene nadoknade je od ključnog značaja, kako bi se finalizirala arhitektura mekog tkiva i poboljšao estetski rezultat. Kondicioniranje mekog tkiva privremenom nadoknadom predstavlja, u odnosu na hiruršku tehniku, manje invazivnu metodu s predvidljivim estetskim ishodom. Njen osnovni nedostatak jeste to što vremenski duže traje. Da bi se potvrdila validnost ove nove tehnike, potrebne su kliničke studije koje bi ispitale dugoročnu stabilnost periimplantatnog mekog tkiva i histološka analiza in vivo koja bi pokazala tačnu strukturu formiranog tkiva.

Tehnika dinamičke kompresije privremenom nadoknadom u estetskoj zoni je klinička metoda koja se zasniva na inicijalnom pritisku i naknadnoj modifikaciji privremene nadoknade stvaranjem prostora u papilarnom predelu. Ovaj klinički rezultat je pokazao da privremene nadoknade na implantatima mogu biti korišćene za oblikovanje izlaznog profila periimplantatnog mekog tkiva, kao i za postizanje odgovarajuće visine i širine interdentalne papile. Privremena nadoknada takođe olakšava komunikaciju između pacijenta, stomatologa i zubnog tehničara i omogućava postizanje predvidljivog i zadovoljavajućeg estetskog rezultata definitivnom nadoknadom.

\section{ZAHVALNICA}

Autori duguju zahvalnost zubnom tehničaru Draganu Spasojeviću. 